\title{
Attitudes Among Male and Female University Professors, and other Categories of University Employees, to Working up to and Beyond Normal Retirement Age
}

\section{Roland Kadefors}

Professor, Department of Sociology and Work Science, University of Gothenburg, Göteborg, Sweden ${ }^{1}$

I Joseph Schaller

Professor, Department of Psychology, University of Gothenburg, Göteborg, Sweden

I Per-Olof Thång

Professor, Department of Education and Special Education, University of Gothenburg, Göteborg, Sweden

1 Elin Pestat

M.S., Department of Psychology, University of Gothenburg, Göteborg, Sweden

\begin{abstract}
A study was undertaken in order to identify variables predicting the willingness of male and female university professors, and other employment categories, to work up to and beyond normal retirement age (65 years). Employees were asked by means of a questionnaire about their willingness to continue working to age 67 , or to age 70 , if they were given the chance. Hierarchical multiple regression analysis was carried out ( $N=3,019 ; 59.8 \%$ women and $40.2 \%$ men). The interest to continue working into old age was significantly higher in men than in women $(p<0.01)$. Among independent variables, age, position, and work satisfaction predicted women's as well as men's interest to work to age 67 and 70, whereas among women perceived health predicted the willingness to work to age 67. Professors and lecturers were the categories showing the highest interest to work to age 70, compared to administrative and technical personnel; men showed significantly higher interest than women among lecturers and administrative personnel. The study emphasizes the effects of position and gender on willingness to continue working into old age, but identifies in addition also work satisfaction and age as significant predictors.
\end{abstract}

\section{KEY WORDS}

retirement intentions / academic employment / gender / older workers / perceived health / work satisfaction

DOI

10.19154/njwls.v6il.4913

\footnotetext{
${ }^{1}$ E-mail: roland.kadefors@socav.gu.se
} 


\section{Introduction}

$\mathrm{t}$ is well known that retirement patterns differ between socioeconomic groups. In a study of the Swedish labor market (Kadefors and Wikman 2011), it was found that there were large differences in work life exit age between occupations; in many blue collar jobs, the average exit age was more than five years lower than that in white collar jobs, particularly low in comparison to higher academic occupations. Reasons behind these occupational differences are undoubtedly in part related to work ability factors (Ilmarinen 2006); in some occupations, many older employees have difficulties to comply with work demands, and are more or less forced to retire early.

As noted by Nilsson et al. (2011), there is a distinction to be made between those who 'can' and those who 'want to' work up to retirement age. Three areas were significantly associated with the outcomes: workers' health, economic incentives, and retirement decisions by life partners or close friends. Mental and physical working environment, work pace, and competence were associated with the 'can' outcome, whereas work as an important part of life, working time, and attitudes of employers were associated with the 'want to' outcome.

In addition to workplace-related factors, gender differences are also significant. In Sweden, women exit from work life earlier than men in most occupations, even though according to recent statistics, the difference is waning (Swedish Social Insurance Agency 2011). In a study based on the Swedish labor force statistics, Soidre (2005) found that the strengths of various push and pull factors (Gruber and Wise 1998) affecting retirement preferences were gender specific: for women, a trying job tended to push them out of the labor market. Women felt less inclined to work after age 65 if they felt superfluous at work, and if they had a positive attitude to the private sphere. On the other hand, men who had a socially rewarding job tended to remain longer in the labor force. Men who worked mainly for economic reasons were more positive to an early exit; likewise, those who felt that they were unappreciated at work preferred early retirement. Significant gender differences were also found by Ahlberg et al. (2002) in a survey of Swedish working people in the age range 25-64 years. Among women, living alone as well as poor social support at work were factors that were negatively correlated to an expectancy of late exit. Among men, negative factors included high physical workload, poor health, and negative experiences of organizational changes at work. Only about $10 \%$ of the respondents declared that they would consider continue working after the official pension age (65 years at the time). Those who were willing to do so included in particular white collar professionals with high-demand, high-control jobs, whereas many blue collar workers hoped for an early exit from work. These findings comply with the demand-control model (Karasek 1979) as well as the mental/physical demand-experience model; high demands at work can be compensated for by organizational freedom and performance benefits from experience (Warr 1994, 2001).

It can be hypothesized that university professors represent an occupational category benefiting from many of the positive job ingredients allowing a prolonged working life in both men and women. On the other hand, the 'publish or perish' culture puts pressure on faculty members to be productive; research productivity lower than average has been found to predict early exit of faculty members from work in the U.S. (Kim 2003).

Job-related demands on male and female professors are basically the same. Is there still a gender effect also in this category? Are there significant job-related factors that are gender 
specific? It would be of interest to map attitudes to working into high age in a university organization with a balanced gender set, and a range of occupations mirroring the labor market with respect to organizational position and requirements of formal education.

\section{Purpose}

The purpose of the present study was to investigate the significance of different factors for male and female university professors with respect to attitudes to continuing working after having reached the normal Swedish retirement age of 65 , to primarily 67 and, subsequent to that, possibly to 70 years. The following research questions were addressed:

1. Does the interest in continuing working up to and past the normal retirement age differ between university professors and other categories of university employees?

2. Can factors such as age, position, perceived health and work satisfaction predict women's and men's willingness to work after reaching normal retirement age?

\section{Materials and Methods}

\section{Study participants}

The present data were collected within the framework of a general work environment inquiry carried out among employees of a major Swedish university. A questionnaire was distributed to all employees. It was completed by 3,685 employees $(72.2 \%$ response rate). The age of the participants varied between 19 and 64 years $(M=46.2, s=11.2)$. Following exclusion of respondents older than 65 years and those working part-time only, 3,019 participants remained $(59.8 \%$ women and $40.2 \%$ men). The respondents (excluding doctoral students) were grouped according to employment categories: professors $(N=310)$, lecturers $(N=1,391)$, administrative personnel $(N=662)$, technical service personnel $(N=384)$.

\section{Measuring instruments}

\section{Dependent variables}

Two questions concerned the attitude of the employees toward continuing work until the age of 67 and 70, respectively. The questions were formulated in the following way:

1. Do you think that you will work until you turn 67 ?

2. If the opportunity would be given after turning 67 to work with the same work tasks as now, would you then consider working until age 70 ?

The answer alternatives for both questions constituted a four-degree scale from 'yes, certainly' to 'no, certainly not' as well as a fifth alternative, 'I have not thought about 
it.' In order to be able to answer the first research question, both questions were dichotomized according to the following: the answer alternatives 'yes, certainly' and 'yes, probably' were coded as ' 1 ' and other answer alternatives as ' 0 .' In the following regression analyses, the dependent variables are used as four-degree scales, from 'yes, certainly' to 'no, certainly not,' in order to be able to answer the second research question.

\section{Independent variables}

As independent variables, a number of individual questions, and even a few groups of questions on which the index was formed, were used. The independent variables were the following:

- Age at the investigation occasion (fall 2008) varied between 19 and 64 years ( $\mathrm{M}=46.2$, $\mathrm{s}=11.2$; net sample).

- Position is a dichotomized variable where the 24 position groups were divided into two groups: 'professor/lecturer' was categorized as ' 1 ' and 'not a professor/lecturer' as ' 0 ' $(\mathrm{M}=0.6, \mathrm{~s}=0.5)$.

- Perceived health on the investigation occasion was judged by the respondents on an eleven-degree scale where ' 0 ' = very bad health and ' 10 ' = very good health $(\mathrm{M}=7.9, \mathrm{~s}=1.9)$.

- Sick leave during the last 12 months is a dichotomized variable where the answer alternative 'no' was categorized as ' 1 ' and 'yes' as ' 2 ' $(\mathrm{M}=1.2, \mathrm{~s}=0.4)$.

- Health concern is a mean index for the employees' concern within five different areas for physical and psychological health risks at work. The answer alternatives were identified on a scale from one to four where a high given value was concern for health risks $(\mathrm{M}=1.8, \mathrm{~s}=0.5)$. Cronbach's $\alpha=0.67$.

Work satisfaction originally consisted of three questions that concerned the employees' thoughts and feelings about the work situation, degree of satisfaction with the work as a whole, and how positive the employees were to working in their department. As the questions had a different number of answer alternatives, they were transformed to a seven-degree scale, where ' 1 ' $=$ completely dissatisfied and ' 7 ' = completely satisfied; thereafter a mean index was formed $(M=5.5, s=1.1)$. Cronbach's $\alpha=0.82$.

\section{Data processing}

After an initial analysis of frequencies, correlations, and group comparisons, four hierarchical multiple regression analyses were carried out in order to clarify the most important influences on the dependent variables. The four regression analyses were constructed through three steps. In the first step, the background variables age and position were included. In the second step, the analysis was expanded with the variables perceived health, sick leave during the last 12 months, and health concern. The variable work satisfaction was added in the concluding third step, since the index contains the variables that the employer has the greatest possibility to affect. 


\section{Results}

A clearly higher percentage of men $(55.0 \%)$ than women $(37.5 \%)$ expressed interest in working to the age of $67\left(\chi^{2}(1, N=3,019)=90.3, p<0.01\right)$. Although the interest decreased in both sexes in reference to working until age 70 , the interest in men was still more than twice as high $(38.9 \%)$ as in the women $(14.5 \%)$. The difference was significant $\left(\chi^{2}(1, N=3,006)=138.8, p<0.01\right)$.

All independent variables showed significant correlations with the two dependent variables. The intercorrelations are shown in Table 1.

In order to study to which extent the variables age, position, perceived health, sick leave during the last 12 months, health concern, and work satisfaction impacted women's and men's interest to work until the age of 67 and 70, respectively, hierarchical multiple regression analysis was used. The result from the first regression analysis shows that the independent variables together explained $12 \%$ of the variance in women's interest in working until 67 years $(p<0.01)$, which can be assessed as a medium effect. Standardized beta coefficients, $t$-values, significance levels, $R^{2}$ and $\Delta R^{2}$ values are reported in Table 2.

Table I Intercorrelations for the survey variables

\begin{tabular}{|c|c|c|c|c|c|c|c|}
\hline Question/Index & I & 2 & 3 & 4 & 5 & 6 & 7 \\
\hline I. Age & - & & & & & & \\
\hline 2. Position & -0.06 & - & & & & & \\
\hline 3. Perceived health & $0.04 *$ & 0.01 & - & & & & \\
\hline 4. Sick leave & $0.04 *$ & $-0.13^{* * *}$ & $-\left.0.2\right|^{* * * *}$ & - & & & \\
\hline 5. Health concern & -0.21 **** & $-0.08 * * * *$ & $-0.35 * * * *$ & $0.12 * * * *$ & - & & \\
\hline 6. Work satisfaction & 0.06 **** & .03 & 0.37 ***** & -0.09 ***** & -0.33 ***** & - & \\
\hline 7. Work to age $67^{\circ}$ & -0.13 **** & $0.29 * * * *$ & $0.13^{* * * *}$ & $-0.10 * * *$ & $-0.12 * * * *$ & 0.14 ***** & - \\
\hline 8. Work to age $70^{\circ}$ & $-0.04 *$ & 0.36 ***** & 0.12 ***** & -0.09 ****** & 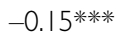 & 0.21 **⿻丷木大 & 0.69**** \\
\hline
\end{tabular}

$a=$ dependent variable. Significant at $* p<0.05$. Significant at $* * * p<0.00$ I.

Table II Hierarchical multiple regression analysis for effect on interest in working until the age of 67: women

\begin{tabular}{|c|c|c|c|c|c|c|c|c|c|}
\hline \multirow[b]{2}{*}{ Question/index } & \multicolumn{3}{|c|}{ Step I } & \multicolumn{3}{|c|}{ Step 2} & \multicolumn{3}{|c|}{ Step 3} \\
\hline & $\beta$ & $t$ & $p$ & $\beta$ & $t$ & $p$ & $\beta$ & $t$ & $p$ \\
\hline Age & -0.14 & -5.65 & 0.00 & -0.16 & -6.27 & 0.00 & -0.16 & -6.28 & 0.00 \\
\hline Position & 0.25 & 10.14 & 0.00 & 0.25 & 10.03 & 0.00 & 0.25 & 10.02 & 0.00 \\
\hline Perceived health & & & & 0.10 & 3.37 & 0.00 & 0.07 & 2.37 & 0.02 \\
\hline Sick leave & & & & -0.05 & -1.86 & 0.06 & -0.05 & -1.91 & 0.06 \\
\hline Health concern & & & & -0.06 & -2.36 & 0.02 & -0.05 & -1.75 & 0.08 \\
\hline Work satisfaction & & & & & & & 0.08 & 2.83 & 0.01 \\
\hline$R^{2}$ & \multicolumn{3}{|c|}{0.09} & \multicolumn{2}{|c|}{0.11} & \multicolumn{4}{|c|}{0.12} \\
\hline$\Delta R^{2}$ & \multicolumn{2}{|c|}{$0.09 * * * *$} & & \multicolumn{2}{|c|}{$0.02 * * * *$} & \multicolumn{4}{|c|}{$0.01 * *$} \\
\hline
\end{tabular}

$N=1,599$. Significant at $* * p<0.0$ I. Significant at $* * * p<0.00$ I. 
The result from Table 2 shows that age and position predicted women's interest in working until the age of 67 in the first step. Two of three variables in the second step, perceived health and health concern, were related to women's interest in working until the age of 67 . In the third step the analysis with the variable work satisfaction expanded, which gave significant results for the variables age, position, perceived health, and work satisfaction, while health concern no longer had a significant contribution. The variable sick leave during the last 12 months did not predict women's interest in continuing work until the age of 67 in any of the three steps of the analysis.

The second regression analysis shows that the independent variables together explained $11 \%$ of the variance in the men's interest in working until the age of $67 \quad(p<0.00)$, which can be assessed as a medium effect. In Table 3 the values were reported for standardized beta coefficients, $t$-values, significance levels, $R^{2}$, and $\Delta R^{2}$.

Table III Hierarchical multiple regression analysis for effect on interest in working until the age of 67: men

\begin{tabular}{|c|c|c|c|c|c|c|c|c|c|}
\hline \multirow[b]{2}{*}{ Question/index } & \multicolumn{3}{|c|}{ Step I } & \multicolumn{3}{|c|}{ Step 2} & \multicolumn{3}{|c|}{ Step 3} \\
\hline & $\beta$ & $t$ & $p$ & $\beta$ & $t$ & $p$ & $\beta$ & $t$ & $p$ \\
\hline Age & -0.11 & -3.78 & 0.00 & -0.13 & -4.38 & 0.00 & -0.13 & -4.40 & 0.00 \\
\hline Position & 0.25 & 8.35 & 0.00 & 0.24 & 7.94 & 0.00 & 0.23 & 7.77 & 0.00 \\
\hline Perceived health & & & & 0.09 & 2.82 & 0.01 & 0.05 & 1.50 & 0.14 \\
\hline Sick leave & & & & -0.00 & -0.13 & 0.06 & -0.00 & -0.12 & 0.91 \\
\hline Health concern & & & & -0.09 & -2.77 & 0.01 & -0.06 & -1.90 & 0.06 \\
\hline Work satisfaction & & & & & & & 0.14 & 4.39 & 0.00 \\
\hline$R^{2}$ & \multicolumn{2}{|c|}{0.08} & & \multicolumn{2}{|c|}{0.10} & & \multicolumn{2}{|c|}{0.11} & \\
\hline$\Delta R^{2}$ & \multicolumn{2}{|c|}{0.08 **** } & & \multicolumn{2}{|c|}{$0.02 * * * *$} & & \multicolumn{2}{|c|}{0.01 米*** } & \\
\hline
\end{tabular}

$N=1,1$ 12. Significant at $* * * p<0.001$.

Table 3 shows that the variables age and position had significant effects in the first step of the analysis. In the second step, the effects were significant for the variables perceived health and health concern. The result from the third step of the analysis shows that the variable work satisfaction had significant main effect, while none of the three health factors had any significant contribution.

The results from the two initial analyses show clear similarities between women's and men's interest in working until the age of 67 . The similarities consist in particular of that both groups received significant results for the variables age, position and work satisfaction in the third step of the analyses. The groups' $R^{2}$ values also rested on similar levels $\left(R^{2}\right.$ women $=0.12, R^{2}$ men $\left.=0.11\right)$. A difference between the groups was, however, that the variable perceived health had a significant impact on the women's interest but not on that of the men.

In the third regression analysis, women's interest in working until the age of 70 is reported, and the independent variables together explained $13 \%$ of the variance $(p<0.00)$, which can be assessed as a medium effect. In Table 4 standardized beta coefficients, 
Table IV Hierarchical multiple regression analysis for effect on interest in working until the age of 70: women

\begin{tabular}{|c|c|c|c|c|c|c|c|c|c|}
\hline \multirow[b]{2}{*}{ Question/index } & \multicolumn{3}{|c|}{ Step 1} & \multicolumn{3}{|c|}{ Step 2} & \multicolumn{3}{|c|}{ Step 3} \\
\hline & $\beta$ & $t$ & $p$ & $\beta$ & $t$ & $p$ & $\beta$ & $t$ & $p$ \\
\hline Age & -0.03 & -1.17 & 0.24 & -0.05 & -1.91 & 0.06 & -0.05 & -1.97 & 0.05 \\
\hline Position & 0.31 & 11.93 & 0.00 & 0.30 & 11.75 & 0.00 & 0.30 & 11.71 & 0.00 \\
\hline Perceived health & & & & 0.07 & 2.52 & 0.01 & 0.03 & 0.96 & 0.34 \\
\hline Sick leave & & & & -0.04 & -1.68 & 0.09 & -0.04 & -1.72 & 0.09 \\
\hline Health concern & & & & -0.08 & -2.67 & 0.01 & -0.04 & -1.54 & 0.12 \\
\hline Work satisfaction & & & & & & & 0.14 & 5.14 & 0.00 \\
\hline$R^{2}$ & \multicolumn{2}{|c|}{0.10} & & \multicolumn{2}{|c|}{0.11} & \multicolumn{4}{|c|}{0.13} \\
\hline$\Delta R^{2}$ & \multicolumn{2}{|c|}{ 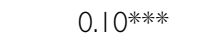 } & & \multicolumn{2}{|c|}{0.0 I ****** } & & \multicolumn{2}{|c|}{$0.02 * * * *$} & \\
\hline
\end{tabular}

$N=1,51$ I. Significant at $* * * * p<0.001$.

$t$-values, significant levels as well as $R^{2}$ and $\Delta R^{2}$ values are reported. The results from Table 4 show that only the variable position received a significant result in the initial step of the analysis. When a check was done for the variables age and position in the analysis' second step, perceived health and health concern received significant results. Nor in the second step could age predict women's interest in working until the age of 70 . When the variable work satisfaction was added to the third step in the analysis, the variables age, position, and work satisfaction could predict women's interest in working until the age of 70 . The variable perceived health did not receive any significant result in the third step, and the variable sick leave during the last 12 months did not receive any significant result in any of the three steps of the analysis.

The result from the fourth regression analysis shows that the independent variables together explained $19 \%$ of the variance in men's interest in working until the age of 70 ( $p<0.00)$. The $R^{2}$ value of 0.19 can, according to Cohen's measure (Cohen 1988), be assessed to rest between a medium and large effect. Standardized beta coefficients, $t$-values, significant levels as well as $R^{2}$ and $\triangle R^{2}$ values are reported in Table 5 .

Table 5 shows that the variables age and position predicted men's interest in working until age 70 in the first step of the analysis. During the check for the above variables, the results show that only the variable perceived health received a significant result in the second step. In the third step the analysis expanded with the variable work satisfaction, which received a significant result, while the variable perceived health did not have a significant contribution anymore. The variables sick leave during the last 12 months and health concern could not predict men's interest in working until the age of 70 in any of the steps. The results in Table 5 show additionally that the percentage of explained variance rose significantly $\left(\Delta R^{2}=0.05\right)$ when all independent variables were included in the analysis.

The two concluding analyses show that there are again similarities between the factors that affected women's and men's interest in continuing to work after retirement age. The similarities are that both groups again received significant results for the variables age, position and work satisfaction in the analyses' third step. $R^{2}$ values for the groups differed, however, this time when the men's value $\left(R^{2}=0.19\right)$ was higher than that of the women's $\left(R^{2}=0.13\right)$. 
Table V Hierarchical multiple regression analysis for effect on interest in working until the age of 70: men

\begin{tabular}{|c|c|c|c|c|c|c|c|c|c|}
\hline \multirow[b]{2}{*}{ Question/index } & \multicolumn{3}{|c|}{ Step I } & \multicolumn{3}{|c|}{ Step 2} & \multicolumn{3}{|c|}{ Step 3} \\
\hline & $\beta$ & $t$ & $p$ & $\beta$ & $t$ & p & $\beta$ & $t$ & p \\
\hline Age & -0.07 & -2.38 & 0.02 & -0.09 & -2.95 & 0.00 & -0.09 & -3.11 & 0.00 \\
\hline Position & 0.35 & 11.45 & 0.00 & 0.35 & 11.26 & 0.00 & 0.34 & 11.20 & 0.00 \\
\hline Perceived health & & & & 0.10 & 3.01 & 0.00 & 0.03 & 0.89 & 0.38 \\
\hline Sick leave & & & & 0.05 & 1.50 & 0.14 & 0.05 & 1.55 & 0.12 \\
\hline Health concern & & & & -0.06 & $-|.8|$ & 0.07 & -0.01 & -0.30 & 0.76 \\
\hline Work satisfaction & & & & & & & 0.24 & 7.39 & 0.00 \\
\hline$R^{2}$ & \multicolumn{2}{|c|}{0.13} & & \multicolumn{2}{|c|}{0.14} & \multicolumn{4}{|c|}{0.19} \\
\hline$\Delta R^{2}$ & \multicolumn{2}{|c|}{$0.13 * * * *$} & & \multicolumn{2}{|c|}{0.01 米米米 } & \multicolumn{4}{|c|}{0.05 ***** } \\
\hline
\end{tabular}

$N=1,015$. Significant at $* * * p<0.001$.

Table VI Interest to work until age 67 among men and women in different occupational groups

\begin{tabular}{llll}
\hline Category & Men $\%$ & Women $\%$ & \\
\hline Professors & $70(N=268)$ & $62(N=81)$ & $\chi^{2}=2.03 \mathrm{~ns}$ \\
\hline Lecturers & $62(N=259)$ & $47(N=240)$ & $\chi^{2}=11.44 * * *$ \\
\hline Administrative personnel & $50(N=123)$ & $28(N=544)$ & $\chi^{2}=23.24 * * *$ \\
\hline Technical personnel & $34(N=160)$ & $29(N=225)$ & $\chi^{2}=1.04 \mathrm{~ns}$ \\
\hline
\end{tabular}

Table VII Interest to work until age 70 among men and women in different occupational groups

\begin{tabular}{llll}
\hline Category & Men $\%$ & Women $\%$ & \\
\hline Professors & $49(N=270)$ & $38(N=81)$ & $\chi^{2}=2.84 \mathrm{~ns}$ \\
\hline Lecturers & $41(N=260)$ & $23(N=239)$ & $\chi^{2}=18.69 * * *$ \\
\hline Administrative personnel & $16(N=122)$ & $7(N=545)$ & $\chi^{2}=11.14 * * *$ \\
\hline Technical personnel & $14(N=160)$ & $8(N=221)$ & $\chi^{2}=3.10 \mathrm{~ns}$ \\
\hline
\end{tabular}

Position was found to represent a significant variable in the analysis. Tables 6 and 7 show that subdividing position further into the four categories professors, lecturers, administrative personnel, and technical personnel entails significant gender differences among lecturers and administrative personnel, but not among professors and technical personnel, with respect to the interest to work to age 67 as well as to age 70 . Professors and lecturers show the highest interest to continue working into high age. 


\section{Discussion}

\section{The effect of position in the organization}

In the present study, professors and lecturers were the categories showing the highest interest to work to age 70, compared to administrative and technical personnel. However, it was noted that the effect of work satisfaction was unrelated to position, indicating that this variable does not depend on whether you have an academic job (professor, lecturer) or a non-academic job (technical or administrative work). Also other factors need to be taken into consideration. Among civil servants Mein et al. (2000) studied significant determinants of intention to retire later; independent predictors of early retirement included employment grade, self-perceived health, and job satisfaction; this set of factors mirrors the findings of the present study.

The high interest noted among professors to continue working into older age, when given a chance, is well known. For instance, in a follow-up to the 1994 decision in the U.S. to abolish the obligatory retirement of tenured faculty at age 70 (Ashenfelter and Card 2002), it was found a few years later that a large portion of the older professors had changed behavior vis-à-vis retirement; less than $30 \%$ of those turning 70 chose to retire, and half of those still working at age 70 were still working at age 72 . Also in Australia it was found that following elimination of obligatory retirement many professors continued to work long after reaching the age of 70 (Anderson et al. 2002). In Canada, it was estimated that $22.7 \%$ of faculty members employed at age 64 at universities without mandatory retirement would continue to be employed at the same university at age 72 (Warman and Worswick 2010). In the present study, the difference between professors and lecturers is of note: professors in the Swedish university organization enjoy a higher degree of organizational freedom compared to lecturers, who tend to be fully occupied with educational duties.

The low interest found among non-academic personnel to work up to or beyond normal pension age complies with the notion that low education, poor health, and low sense of coherence (related to work satisfaction) are the best predictors for intentions to retire early (Volanen et al. 2010).

\section{Gender and views on retirement}

The present study showed that the interest to continue working into old age among employees in a university organization was significantly higher among men than among women. Age, position, and work satisfaction predicted women's as well as men's interest to work to age 67 and 70, whereas among women also perceived health predicted the willingness to work to age 67.

The gender differences observed comply in part with the observations in a German study by Büsch et al. (2010); they found that in men, high motivation (meaningful work) was linked to the desire for continued employment in retirement, whereas in women, work ability, which is a health-related factor, was the decisive criterion. They concluded that 'in particular, meaningful work increases motivation among men and work ability increases motivation among women.' Likewise, 'importance of work' was found in an Australian study by Shacklock et al. (2009) to be a significant factor influencing men's, 
but not women's intention to continue working. Our finding that job satisfaction was a significant factor also among women could reflect conditions specific to a university organization, but possibly also other attitudes held by Swedish women, compared to Germany and Australia.

Among factors influencing the decision to retire, the decision made by the life partner to retire may have a strong impact (Nilsson et al. 2011). It was found in a study in the U.S. that within a marriage, retirement expectations were shaped by individual, spousal and household characteristics, and that wives' retirement expectations were more influenced by husbands' resources and constraints than vice versa (Pienta and Hayward 2002). Retirement intentions have also been found to relate to the level of marital quality (Henkens and Leenders 2010); older workers who reported a higher level of marital quality also reported a stronger intention to retire. At the individual level, pull factors may be as important as push factors when it comes to the decision whether or not to continue working into higher age. Since the husband is older than the wife in most relationships, and the husband may be eligible for retirement earlier on than the wife, this noted difference in influence may provide a partial explanation for the lower interest that we have found among women to carry on working into older age.

In the present study, the age distribution differed somewhat between men and women; the percentages in the age range $60+$ were 19.9 and 17.2 respectively, and in the range below 30 years, 9.3 and $7.9 \%$. Since older respondents tended to look less favorably on continuing work to age 67 and above, this means that the gender difference observed tends to be slightly downplayed in the analysis.

\section{Effect of age and perceived health}

Poor health has been identified as a major factor pushing employees into retirement (e.g., Feldman 1994). According to Ilmarinen (2001), health and functional capacities form the basis for human resources and work ability generally. The fact that perceived health was a predictive factor in women but not in men in our study can be interpreted as a difference in attitudes to work in accordance with the findings by Büsch et al. (2010), implying that meaningful work increases motivation to work into older age in men, whereas women are more inclined to take into account their work ability.

Physical ailments are a major cause behind age-related deterioration in work ability (Ilmarinen 2001). In a university environment, the physical workload may be modest for all employee categories in comparison with many other branches in the labor market; even those university employees who have some health problems may find it possible to match job demands, provided work is perceived motivating. For instance, according to Karasek (1979), the adverse health effects of high work demands are buffered by influence at work; insufficient levels of influence at work enhance the adverse health effects of high work demands.

It was found that age was a significant factor for the interest to work up to age 65 as well as to work until age 70, for all employment categories. Younger men and women showed higher interest than older ones, which in part may reflect impaired health and reduced work ability among older employees; work-related effects on health impairing work ability tend to increase with age (Ilmarinen 2006, pp. 158-211). 


\section{Effect of work satisfaction}

It is of note that in the present study, work satisfaction was identified as a main factor predicting intention to retire or to continue working into higher age, irrespective of organizational position and sex. This is in agreement with results from earlier research covering a wide spectrum of occupations (e.g., Buyens et al. 2009; Kautonen et al. 2012; Sibbald et al. 2003). For instance, in a study of retirement intentions among employees of a large public employer, Oakman and Wells (2013) found that of work factors that were analyzed, low job satisfaction indicated an increased likelihood of retiring soon.

In a situation where it is of interest to prolong working life generally, these observations are of particular significance, since job satisfaction as well as perceived health are conditions that can be addressed at the workplace level. Theoretical points of departure include the control-demand model (Karasek 1979), the work ability model (Ilmarinen 2001), and the age management model (e.g., Mykletun et al. 2012).

There is a widespread view that in order to achieve a longer working life for large groups in the labor market, it is sufficient to create economic incentives (Swedish Pension Age Commission 2013). However, it may well be that investing in measures enhancing conditions at work is even more powerful. Universities, which may need to preserve the competence in the organization by making older employees continue working more years, should take action to identify what may cause work dissatisfaction as well as poor health appraisal among employees, in order to find out what measures to be taken.

\section{Limitations of the study}

The correlation between the intended retirement age and the actual decision when to retire is rather weak; the relation between intention and behavior has been found to vary primarily by health, education, and type of work (Solem et al. 2014). Nevertheless, intention studies are important, since they give employers an indication of a possible upcoming competence crisis in the organization, and an incitement to address conditions at work.

The present study made possible statistical evaluation entailing some clear and unambiguous results for men and women and different occupational groups. However, the university organization may not be entirely representative of the labor market at large. For instance, physical demands at work may play a dominating role impairing work ability in many other sectors of working life. On the other hand, and for this very reason, analysis of the influence of factors unrelated to musculoskeletal ailments may be facilitated. Studies of gender effects are facilitated in the university organization, being balanced with respect to male and female employment.

It should be noted that the response to the question, 'If the opportunity would be given after turning 67 to work with the same work tasks as now, would you then consider working until age 70 ?' does not necessarily constitute a prediction of retirement from the labor market, but marks an intention vis-à-vis the present employer and the present work tasks. There is a distinction to be made between retirement intention and turnover intention (Schmidt and Lee 2008); affective organizational commitment predicts turnover intention, but not retirement. Administrative and technical service personnel may be more apt than professors/lecturers to look for employment outside the 
university organization; such a 'jump' effect (e.g., Jensen 2005) in these categories is a possible confounder in the present context.

As noted by van Solinge and Henkens (2005), national institutional frameworks concerning pension systems and retirement may have a strong influence on attitudes and behavior. Such differences may imperil direct transnational interpretations. Nevertheless, the results of the present study should remain relevant in the Nordic countries, having much in common with respect to the organization and functioning of the national labor markets.

\section{Suggestions for further research}

The present study demonstrates that there are gender differences and also that age, position, perceived health, and work satisfaction predict late exit from working life. But the decision of an individual person whether or not to continue working into high age may be influenced also by other factors, unrelated to the work situation. There is support for the notion that the decisions about when to retire are complex and formulated over many years (e.g., Ekerdt et al. 2000). In order to gain a better understanding of the relative importance of work-related and work-unrelated factors, we see the need for following up questionnaire studies, such as the present, with interview studies. As noted by Mein et al. (2000), 'qualitative analyses may further advance our understanding of the retirement process.' It is also important to take into account that what people may feel inclined to do is not necessarily what they actually decide (Solem et al. 2014); for this reason, more longitudinal cohort studies should be undertaken.

\section{Acknowledgment}

This research was supported by the Swedish Research Council for Health, Working Life and Welfare (Forte) 2012-1696; 2013-2300.

\section{References}

Ahlberg, G., Marklund, S., Stenlund, C., Torgén, M. (2002). Anställdas arbetssituation, hälsa och attityder. [Work situation, health and attitudes among employees.] Swedish Government Official Report SOU 2002: 5, annex 2:2.

Anderson, D., Johnson, R., Saha, L. (2002). Changes in Academic Work. Implications for Universities of the Changing Age Distribution and Work Roles of Academic Staff. Canberra: Commonwealth of Australia.

Ashenfelter, O., Card, D. (2002). Did the elimination of mandatory retirement affect faculty retirement? American Economic Review 957-980. doi: http://dx.doi.org/10. $1257 / 00028280260344542$.

Büsch, V., Dittrich, D., Lieberum, U. (2010). Determinants of work motivation and work ability among older workers and implications for the desire for continued employment. Comparative Population Studies-Zeitschrift für Bevölkerungswissenschaft 35: 931-958.

Buyens, D., Van Dijk, H., Dewilde, T., De Vos, A. (2009). The aging workforce: perceptions of career ending. Journal of Managerial Psychology 24: 102-117. doi: http://dx.doi. org/10.1108/02683940910928838. 
Cohen, J. (1988). Statistical Power Analysis for the Behavioral Sciences (2 ${ }^{\text {nd }}$ edition). Hillsdale, NJ: Lawrence Erlbaum Associates.

Ekerdt, D. J., Kosloski, K., DeViney, S. (2000). The normative anticipation of retirement by older workers. Research on Aging 22(1): 3-22. doi: http://dx.doi.org/10.1177/ 0164027500221001.

Feldman, D. C. (1994). The decision to retire early: a review and conceptualization. Academy of Management Review 19: 285-311. doi: http://dx.doi.org/10.2307/258706.

Gruber, J., Wise, D. (1998). Social security and retirement: an international comparison. The American Economic Review, Papers and Proceedings 88(2): 158-163.

Henkens, K., Leenders, M. (2010). Burnout and older workers' intentions to retire. International Journal of Manpower 31(3): 306-321.

Ilmarinen, J. (2001). Aging workers. Occupational Medicine 58: 546-552. doi: http://dx.doi. org/10.1136/oem.58.8.546.

Ilmarinen, J. (2006). Towards a Longer Worklife! Ageing and the Quality of Worklife in the European Union. Helsinki: Finnish Institute of Occupational Health.

Jensen, P. H. (2005). Reversing the trend from 'early' to 'late' exit: push, pull, and jump revisited in a Danish context. The Geneva Papers 30: 656-673.

Kadefors, R., Wikman, A. (2011). Inklusion och exklusion. Om arbetslivslängd i olika yrken. [Inclusion and exclusion. On work life length in different occupations.] Arbetsliv $i \mathrm{Om}$ vandling 3: 124-141.

Karasek, R. A. (1979). Job demands, job decision latitude, and mental strain: Implications for job redesign. Administrative Science Quarterly 24: 285-309. doi: http://dx.doi. org/10.2307/2392498.

Kautonen, T., Hytti, U., Bögenhold, D., Heinonen, J. (2012). Job satisfaction and retirement age intentions in Finland: self-employed versus salary earners. International Journal of Manpower 33: 424-440.

Kim, S. (2003). The impact of research productivity on early retirement of university professors. Industrial Relations 42(1): 106-125. doi: http://dx.doi.org/10.1111/1468-232X.00280.

Mein, G., Martikainen, P., Stansfeld, S. A., Brunner, E. J., Fuhrer, R., Marmot, M. G. (2000). Predictors of early retirement in British civil servants. Age and Ageing 29:529-536. doi: http://dx.doi.org/10.1093/ageing/29.6.529.

Mykletun, R., Furunes, T., Solem, P.-E. (2012). Managers' beliefs about measures to retain senior workforce. Nordic Journal of Working Life Studies 2: 109-127.

Nilsson, K., Rignell-Hydbom, A., Rylander, L. (2011). Factors influencing the decision to extend working life or retire. Scandinavian Journal of Work, Environment and Health 37: 473-480. doi: http://dx.doi.org/10.5271/sjweh.3181.

Oakman, J., Wells, Y. (2013). Retirement intentions: what is the role of push factors in predicting retirement intentions? Ageing \& Society 33: 988-1008. doi: http://dx.doi. org/10.1017/S0144686X12000281.

Pienta, A. M., Hayward, M. (2002). Who expects to continue working after age 62? The retirement plans of couples. Journal of Gerontology 57B: 199-208. doi: http://dx.doi. org/10.1093/geronb/57.4.S199.

Schmidt, J., Lee, K. (2008). Voluntary retirement and organizational turnover intentions: the differential associations with work and non-work commitment constructs. Journal of Business Psychology 22: 297-309. doi: http://dx.doi.org/10.1007/s10869-008-9068-y.

Shacklock, K., Brunetto, Y., Nelson, S. (2009). The different variables that affect older males' and females' intentions to continue working. Asia Pacific Journal of Human Resources 47: 79-101. doi: http://dx.doi.org/10.1177/1038411108099291.

Sibbald, B., Bojke, C., Gravelle, H. (2003). National survey of job satisfaction and retirement intentions among general practitioners in England. British Medical Journal 326: 1-4. doi: http://dx.doi.org/10.1136/bmj.326.7379.22. 
Soidre, T. (2005). Retirement-age preferences of women and men aged 55-64 years in Sweden. Ageing and Society 25: 943-963. doi: http://dx.doi.org/10.1017/S0144686X05004216.

Solem, P. E., Syse, A., Furunes, T., Mykletun, R. J., De Lange, A., Schauffeli, W., Ilmarinen, J. (2014). To leave or not to leave: retirement intentions and retirement behaviour. Ageing and Society. doi: http://dx.doi.org/10.1017/S0144686X14001135.

van Solinge, H., Henkens, K. (2005). Couple's adjustment to retirement: a multi-actor panel study. Journal of Gerontology 60B: 11-20. doi: http://dx.doi.org/10.1093/geronb/60.1.S11.

Swedish Pension Age Commission (2013). Åtgärder för ett längre arbetsliv. [Measures for a longer working life.] Swedish Government Official Report, SOU 2013: 25.

Swedish Social Insurance Agency (2011). Nya ohälsomått inom sjukförsäkringen. [New disorder measures in health insurance.] Social Insurance Report 2011: 6.

Volanen, S.-M., Suominen, S., Lahelma, E., Koskenvuo, K., Koskenvuo, M., Silventoinen, K. (2010). Sense of coherence and intentions to retire early among Finnish women and men. BMC Public Health 01/2010; doi: http://dx.doi.org/10.1186/1471-2458-10-22.

Warman, C., Worswick, C. (2010). Mandatory retirement rules and the retirement decisions of university professors in Canada. Labor Economics 17(6): 1022-1029. doi: http://dx.doi.org/10.1016/j.labeco.2010.04.014.

Warr, P. (1994). Age and employment. In: M. D. Dunette and L. M. Hough (eds.), Handbook of Industrial and Organizational Psychology. Palo Alto: Consulting Psychologists Press, 485-550.

Warr, P. (2001). Age and work behaviour: physical attributes, cognitive abilities, knowledge, personality traits and motives. In: C. L. Cooper and I. T. Robertson (eds.), International Review of Industrial and Organizational Psychology. Chichester: Wiley 16: 1-36. 